\title{
STUDIES ON IMPROVEMENT OF PERFORMANCE OF COMPRESSION IGNITION ENGINE FUELLED WITH MIXTURE OF HONGE BIODIESEL AND TIRE PYROLYSIS OIL
}

\author{
KAPILAN Natesan ${ }^{1}$, JULLYA Naik ${ }^{2}$ \\ ${ }^{1}$ Faculty of Mechanical Engineering, Nagarjuna College of Engg. and Technology, Bengaluru, 562164, India \\ email: kapil_krecmech@yahoo.com \\ ${ }^{2}$ Faculty of Mechanical Engineering, NCET, Visvesvarya Technological University, Belagavi,590018, India \\ email: ljnaiksrsit@gmail.com
}

\begin{abstract}
The biodiesel has lower volatility and is costlier than the fossil diesel. Hence it is necessary to add a low cost fuel which has higher volatility, with the diesel. The tire pyrolysis oil (TPO) produced from waste tire and tubes have these desirable properties and hence in this work, we have mixed TPO with biodiesel to enhance the properties of the biodiesel. The engine tests were carried out on a single cylinder compression ignition engine with the mixture of biodiesel and TPO as fuel. From the engine tests, it is observed that the fuel mixture results in engine performance close to diesel operation at the higher injector nozzle opening pressure.
\end{abstract}

KEYWORDS: Alternative fuel, tire pyrolysis oil, biodiesel, engine tests, performance, emission

\section{Introduction}

The social and economic development of any country depends upon the availability of energy resources. The economic growth of any country may be affected by the depletion of fossil fuels, increase in fossil fuel prices and climatic change etc. Hence researchers are finding suitable alternative renewable and sustainable energy technologies world-wide [1]. In recent years, few countries across the world are started using renewable energy sources such as biofuel, solar energy, ocean energy and geothermal energy to ensure energy security and for sustainable growth. Few researchers suggested that the biodiesel is one kind of biofuel that is renewable, biodegradable and has properties comparable to the fossil diesel [2]. The legislations in few countries are formed to reduce prices of the fossil fuels and also engine exhaust emissions. The biofuel based alternative fuels increase the energy security and employability of the region where the biofuel is produced. Few researchers reported that the genetically modified biodiesel fuels can be used into the diesel engine for better environmental and economic results [3]. The biodiesel is defined as the monoalkyl esters of long-chain fatty acids derived from vegetable oils and fats. The use of edible oil feedstocks for biodiesel production has led to several controversial issues including fuel versus food competition. Hence non-edible oils or waste cooking oil or fats are considered as the feedstock for the biodiesel production [4].

India is a developing country and imports more than $70 \%$ of her petroleum oil from other countries. The government of India has taken necessary steps to reduce the demand of petroleum products as the substitution of a small fraction of total consumption of petroleum products by alternative fuels will have a significant impact on the economy and the environment. In India, biodiesel is produced from non-edible oils to reduce the cost of the biodiesel and also to avoid the fuel versus food issue. In India, the honge oil has significant 
potential for biodiesel production and hence we have used it as the raw material for the biodiesel production. Figure 1 shows the honge tree. In India, biodiesel is costlier than the fossil diesel and hence the addition of another low cost fuel may reduce the operating cost of the diesel engine. Hence waste tire pyrolysis oil which is currently receiving renewed interest among the researchers was used in this work as partial substitute for the biodiesel.

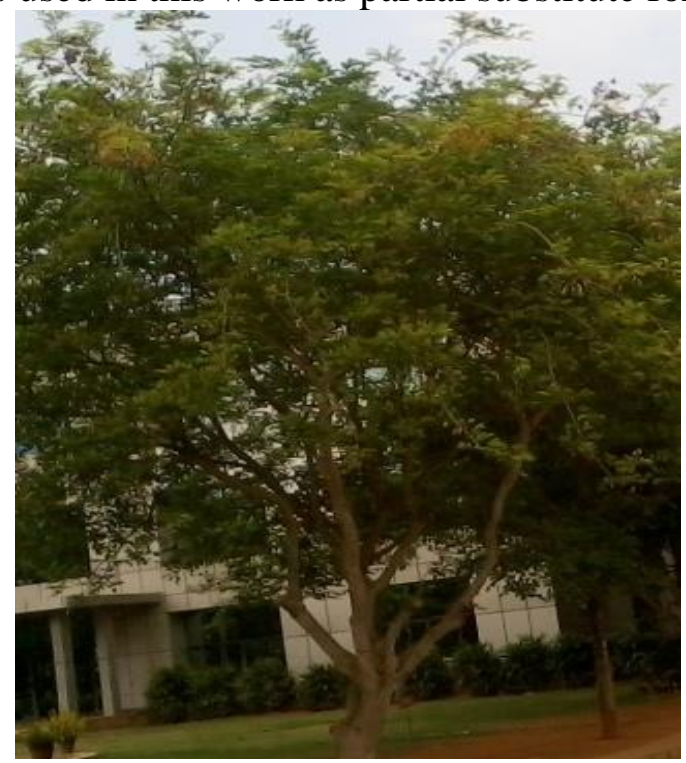

Fig. 1 Honge tree

The improper disposal of waste tire and tubes may lead to risk of fire and toxic smoke and other risks which include the stagnant water in tire that provides breeding grounds for mosquitoes. These problems may be overcome by the pyrolysis process of waste tire and tubes. India is facing issues related to disposal of waste automobile tire and tubes and if these materials are used as fuel, then there will be proper collection system for waste tire and tubes. India account for about 6 to $7 \%$ of the global waste tire and the local tire industry growth in India is $12 \%$ per annum [5]. Figure 2 shows the waste tire.

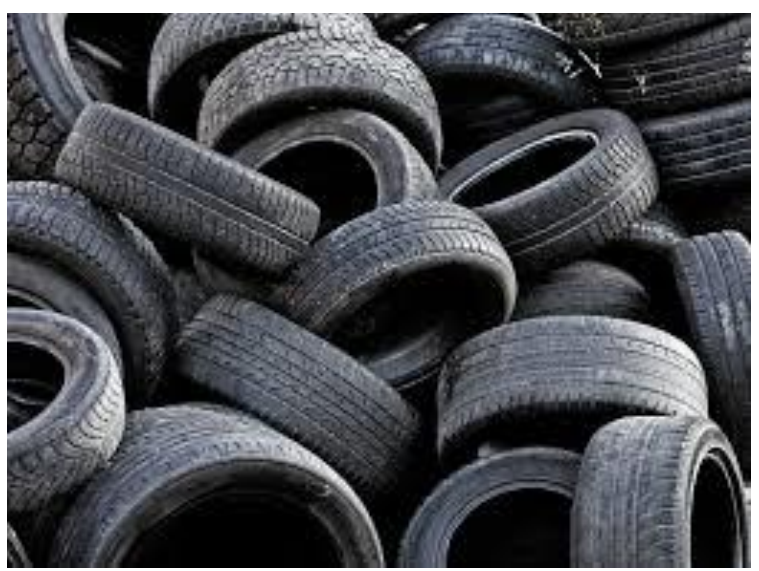

Fig. 2 Waste tire

The pyrolysis process is thermo-chemical decomposition and in this process, shredded tires are heated in a reactor vessel containing an oxygen-free atmosphere. During this process, the rubber is softened after which the rubber polymers break down into smaller molecules. These smaller molecules eventually vaporize and can be condensed into liquid and this liquid is called as tire pyrolysis oil. If this process is a clean operation then it produces little emissions. Few researchers suggested that the pyrolysis is becoming a promising alternative to tackle the waste disposal problem related to waste tire as well as for the production of alternative liquid fuel [6]. 
Few researchers carried-out pyrolysis of waste tire to produce TPO by catalytic distillation and reported that the product had $40 \%$ TPO product with $42 \%$ char, and the remaining $18 \%$ was released to atmosphere as gaseous by product. The TPO was mixed with additives such as natural zeolite and lime, at different mass ratio. They reported that the lime mixture fuel sample at $10 \mathrm{wt} \%$ ratio shown the best results. They also reported that the characteristics of those light and heavy fuels were resembled to those of gasoline and diesel fuel [7]. Ma Xiaolong et al compared the vacuum pyrolysis with retorting and nitrogen sweeping pyrolysis, based on the yields and the properties of the pyrolysis products. The samples of oil sands were heated in the pyrolysis process to the final reaction temperature under varying heating rates and varying vacuum pressures and it is observed that the effect of the reactor heating rate on the liquid oil yield of the pyrolysis reactions became less significant. They reported that longer vapor residence times lead to higher gas and coke yields and lower liquid yields [8]. Siyi Luo et al used the sensible heat of blast-furnace (BF) slag for the production of fuel oil and studied the effects of various operating parameters on yields. They reported that the presence of $\mathrm{BF}$ slag greatly improved the production of derived-oil and increased the contents of $\mathrm{H}_{2}$ and $\mathrm{CO}$ in pyrolysis gases. It was observed that the presence of $\mathrm{BF}$ slag decreased viscosity, density, $\mathrm{H}$ and $\mathrm{O}$ content and increased $\mathrm{C}$ content, $\mathrm{C} / \mathrm{H}$ ratio and calorific value of derived-oil relative to pyrolysis oil derived from solely tire powder, thereby resulting in upgradation of oil quality [9].

Yunpu et al used microwave-assisted catalytic fast co-pyrolysis of waste tires and used bamboo saw dusts for bio-oil production with HZSM-5 as the catalyst. They reported that the optimal co-pyrolysis temperature was $550{ }^{\circ} \mathrm{C}$, which provides the maximum bio-oil yield and lowest proportion of polycyclic aromatic hydrocarbons. They reported that the maximum yield of aromatic hydrocarbons obtained when the optimal bamboo sawdust to waste tire ratio was $1: 1$ [10]. Few researchers studied the pyrolysis and gasification of tires in a pilot plant reactor at 450,750 , and $1000{ }^{\circ} \mathrm{C}$ both in nitrogen and $10 \%$ oxygen atmospheres. They reported that the methane and benzene yields increase with temperature until $1000{ }^{\circ} \mathrm{C}$ in gas phase and in the liquids, the main components are styrene, limonene, and isoprene. They observed that the solid fraction increases with temperature [11]. Erick RyoitiUmeki et al compositional analysis of pyrolytic oil describes the liquid as a complex mixture, composed mainly of aromatic compounds and olefins. They reported that the oil has the density of $0.93 \mathrm{~g} \mathrm{~cm}^{-3}$ and the research octane number (RON) is similar to the RON for Premium gasoline. They also observed that the oil has the high heat value in-between than that for gasoline and diesel fuel, achieving $42 \mathrm{~kJ} \mathrm{~g}^{-1}$ and the tire pyrolysis oil is miscible with diesel in the entire concentration range. They concluded that the blend properties highlight the complexity of the chemical interactions between the fuels, which need consideration before their applications [12]. M. N. Islam and M. R. Nahian reported that the distilled tire pyrolysis oil is similar to diesel fuel and able to replace diesel fuel in small engine. They also reported that the blends of DTPO 25 (75\% diesel with $25 \%$ distilled pyrolysis oil) give better results than DTPO 50 (50\% diesel with 50\% distilled pyrolysis oil) and DTPO 75 (25\% diesel with $75 \%$ distilled pyrolysis oil). They observed that the brake specific fuel consumption of DTPO 25 blend is very close to the specific fuel consumption of diesel. They concluded that the DTPO 25 blend can be directly utilized in diesel engine without any engine modification [13].

De Marco Rodriguez et al produced pyrolysed car tyre under nitrogen in a 3.5 $\mathrm{dm}^{3}$ autoclave at $300^{\circ} \mathrm{C}, 400^{\circ} \mathrm{C}, 500^{\circ} \mathrm{C}, 600^{\circ} \mathrm{C}$ and $700^{\circ} \mathrm{C}$. They reported that the temperature above $500^{\circ} \mathrm{C}$ does not have any influence on the amount and characteristics of pyrolysis products. They have reported high gross calorific values and about $30 \mathrm{wt} \%$ of such liquids is an easily distillable fraction with boiling points $\left(70-210^{\circ} \mathrm{C}\right)$ in the range of commercial petrol. Approximately $60 \mathrm{wt} \%$ of them have the boiling point range $\left(150-370^{\circ} \mathrm{C}\right)$ typical of 
diesel oil [14]. Pilusa investigated tyre-derived fuel oil collected from a local waste tyre treatment facility, refined via a novel oxidative gas-phase fractional distillation, as substitute for diesel. He reported that the engine performance tests results did not show any sign of engine ceasing or knocking effect. He observed that the power-torque trend was very consistent and compared well with diesel [15].

Ertaç Hürdoğan et al used blends of waste tire pyrolysis oil (WTPO) and diesel as fuel in a four stroke, four cylinders, naturally aspirated, direct-injected diesel engine. They reported that the WTPO-diesel blends give similar performance with diesel fuel in terms of torque and power output of the test engine. They also suggested that the blends of pyrolysis oil of waste tire WTPO10 (90\% diesel with 10\% WTPO) can efficiently be used in diesel engines without any engine modifications [16]. Chríbik Andrej used synthesis gas produced from pyrolysis of plastics, in petrol engine and they suggested that the synthesis gas has similar properties as natural gas, in terms of burning. They reported that burning synthesis gas leads to decreased performance by about 5\% and to increased mass hourly consumption by $120 \%$ [17]. Few researchers reported that the fluids injection has a crucial influence on the internal flows [18]. It is reported that the combustion duration of fuel increased significantly even with smaller concentration of honge oil in the fuel blend. The engine emissions such as $\mathrm{HC}, \mathrm{CO}$ and Smoke emissions were found to decrease for $20-50 \%(\mathrm{v} / \mathrm{v})$ honge oil content in the fuel blends [19]. However the honge biodiesel has lower oxidation stability [20].

\section{Materials and Methods}

In this work, TPO commercially available in Bengaluru, India was used as partial substitute for the biodiesel. The TPO was filtered using filter paper to remove the impurities. The biodiesel was prepared from non-edible honge oil using a two-step transesterification process. The honge biodiesel and TPO was mixed in the ratio of 80:20 by volume basis and the mixture was used as fuel.

The engine tests were carried out on a single cylinder naturally aspirated compression ignition engine. The engine details are shown in the Table 1 . The engine was loaded using an eddy current dynamometer.

Table 1 Engine details

\begin{tabular}{|l|l|}
\hline Engine & $\begin{array}{l}\text { Single cylinder, four stroke, naturally aspirated, } \\
\text { direct injection, compression ignition engine }\end{array}$ \\
\hline Make & Kirloskar \\
\hline Displacement $(\mathrm{cc})$ & 661 \\
\hline Maximum Brake Power $(\mathrm{kW})$ & 5.2 \\
\hline Rated Speed $(\mathrm{rpm})$ & 1500 \\
\hline Bore $(\mathrm{mm})$ & 87.5 \\
\hline Stroke $(\mathrm{mm})$ & 110 \\
\hline Injection Time & 23 degree bTDC \\
\hline
\end{tabular}

The engine setup is provided with necessary instruments for recording the observations such as airflow, fuel flow, temperatures and load measurement. The set up has stand-alone panel box consisting of air box, fuel tank, manometer, fuel measuring unit, transmitters for air and fuel flow measurements and process indicator. A rotameter was used to measure the cooling water flow rates.

The engine experimental setup is shown in the Figure 3. The engine emissions were measured using an AVL make exhaust gas analyzer and its details are given in Table 2. The engine tests were conducted at constant speed. Initially the engine tests were conducted with 
diesel to get baseline data and the injector nozzle opening pressure (INOP) of diesel was maintained at 180 bar. Then the fuel mixture was used as the fuel and important observations and emissions were recorded. All the experiments were conducted thrice and average value was taken. The INOP was varied and the values considered were 180, 200 and 220 bar.

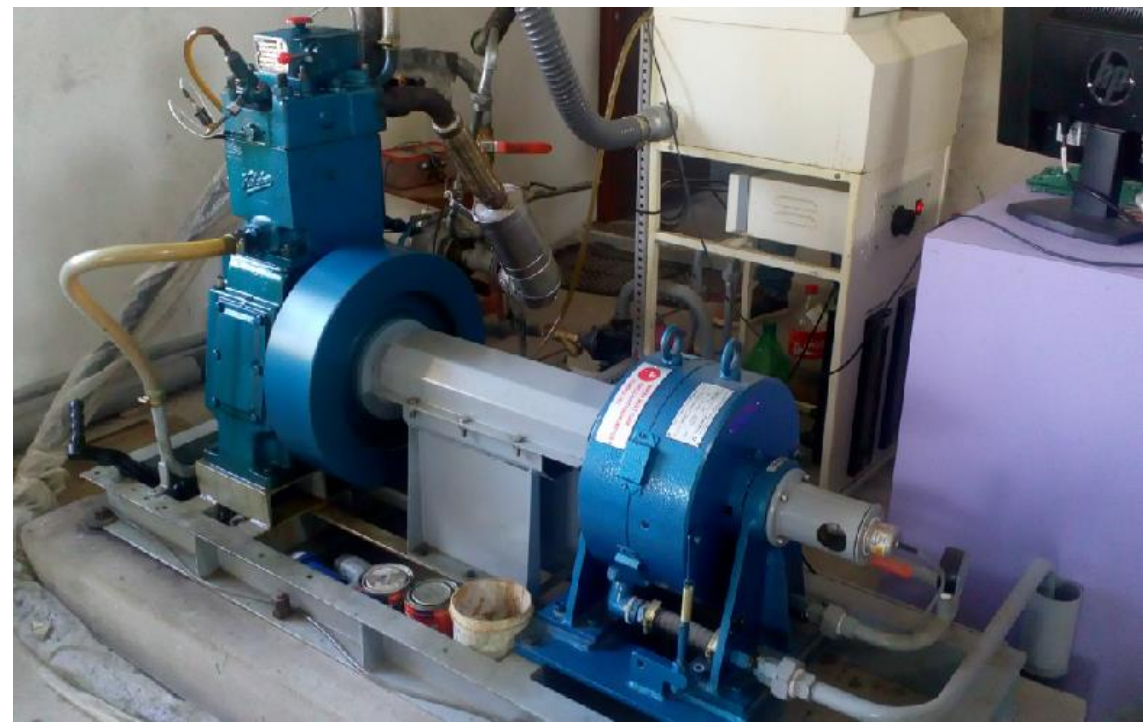

Fig. 3 Engine experimental setup

Table 2 Exhaust gas analyser

\begin{tabular}{|l|l|}
\hline Smoke meter & Make : AVL 437C \\
\hline Exhaust Gas Analyzer & Make : AVL India Pvt Ltd AVL Digas 444 N \\
\hline Quality & Range \\
\hline CO (\% vol) & $0-15$ \\
\hline HC (ppm) & $0-30000$ \\
\hline NOx (ppm) & $0-5000$ \\
\hline Range (\%) & $0-100$ \\
\hline Resolution (\%) & 0.1 \\
\hline
\end{tabular}

\section{Results and Discussion}

The mixture of TPO and honge biodiesel was prepared and was successfully used as fuel in the compression ignition engine. Table 3 compares the properties of the mixture of fuel, diesel and biodiesel. From the table it is observed that the properties of the biodiesel were improved by the addition of TPO.

Table 3 Properties of Fuels

\begin{tabular}{|l|c|c|c|}
\hline \multicolumn{1}{|c|}{ Property } & Diesel & Biodiesel & Fuel Mixture \\
\hline Viscosity $\left(\mathrm{mm}^{2} / \mathrm{s}\right)$ & 2.5 & 4.1 & 3.9 \\
\hline Calorific Value $(\mathrm{MJ} / \mathrm{kg})$ & 42.04 & 37.1 & 39.6 \\
\hline Density $\left(\mathrm{kg} / \mathrm{m}^{3}\right)$ & 845 & 887 & 877 \\
\hline Flash Point $\left({ }^{\circ} \mathrm{C}\right)$ & 59 & 151 & 108 \\
\hline Fire Point $\left({ }^{\circ} \mathrm{C}\right)$ & 65 & 167 & 119 \\
\hline
\end{tabular}


The effect of fuel injector nozzle opening pressure (INOP) on the brake thermal efficiency (BTE) of the engine at different loads is shown in the Figure 4. From the figure it is observed that, as the load increases the BTE increases. This is due to lower frictional losses at the higher loads. The efficiency of the diesel engine is affected by the INOP and the INOP of 200 bar results in higher BTE as compared to other INOPs. This is due to the better atomization and mixing of fuel and air. The INOP of 180 bar results in lower BTE due to poor atomization and spray formation at higher loads. However the BTE of the mixture of fuel is lower than the diesel.

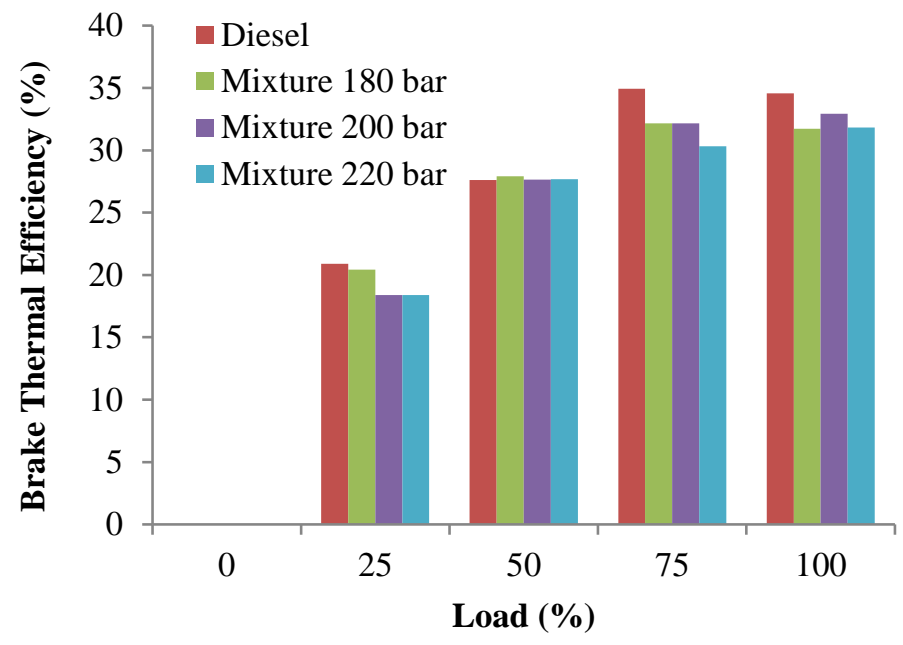

Fig. 4 BTE Versus Load

Figure 5 shows the effect of INOP on the exhaust gas temperature (EGT) at different loads. From the figure it is observed that as the load increases the EGT increases and this is due to increase in fuel flow rate at higher and full loads. The figure shows that the EGT of mixture of fuel is lower than the diesel. The EGT of the engine is affected by the INOP and the INOP of 220 bar results in higher EGT at lower load. The INOP of 200 bar results in lower EGT as compared to other INOPs. The INOP of 220 bar results in lower EGT as compared to 180 bar at higher loads.

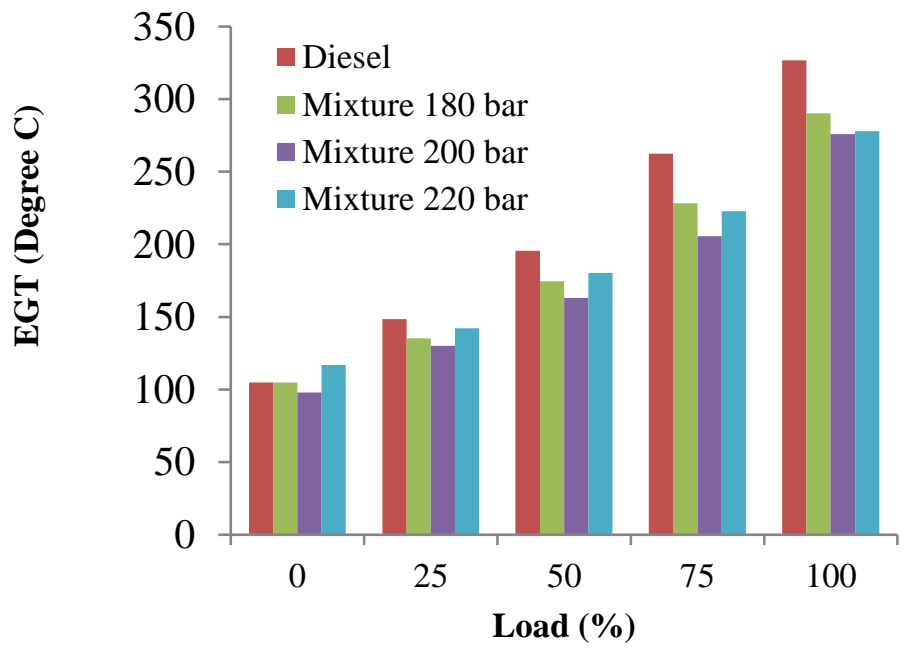

Fig. 5 EGT Versus Load 
The variation of carbon monoxide (CO) emission with different fuels at various INOP is shown in the Figure 6. From the figure it is observed that the $\mathrm{CO}$ emission is low at low loads and at part loads. This may be due to better combustion of the fuel. However the $\mathrm{CO}$ emission increases at higher loads due to supply of higher amount of fuel which may results in incomplete combustion of the fuel. There is a slight difference in the $\mathrm{CO}$ value of the fuels at part loads. However the fuel mixture of TPO and biodiesel results in higher CO emission at full load as compared to the diesel. The INOP of 200 bar results in lower CO emission as compared to other INOPs. The INOP of 220 bar results in higher CO emission and this may be due to poor spray formation and incomplete combustion of the fuel.

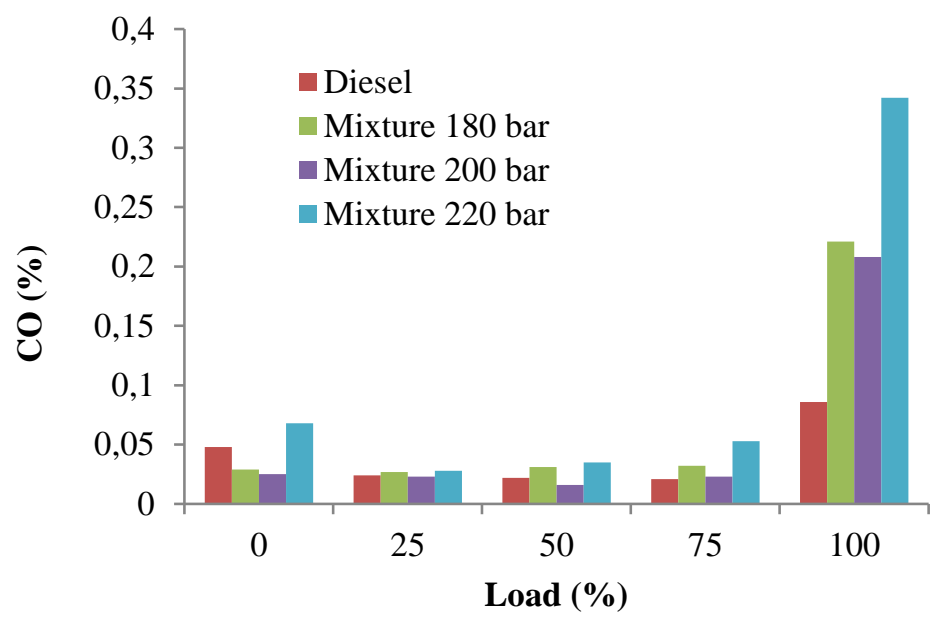

Fig. 6 CO Versus Load

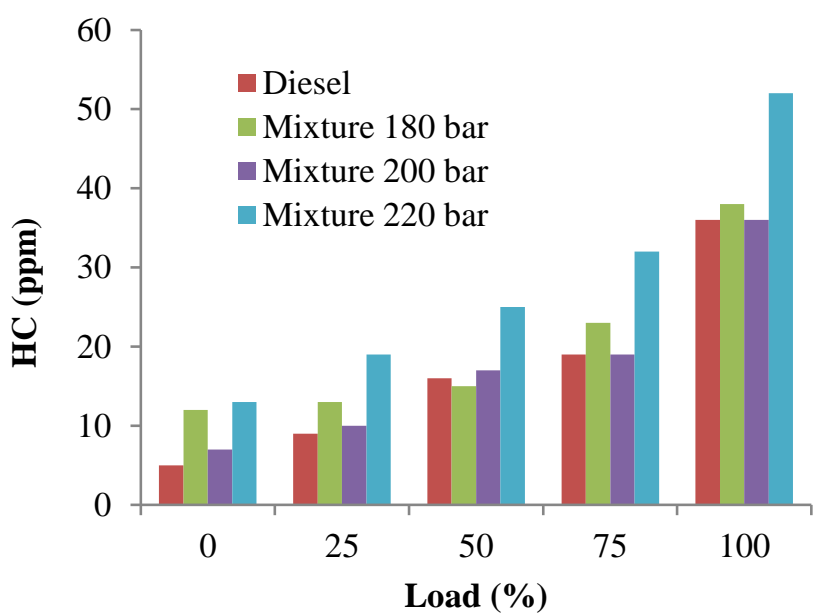

Fig. 7 HC Versus Load

Figure 7 shows the effect of INOP on the hydrocarbon (HC) emission of the engine with different fuels. From the figure, it is observed that $\mathrm{HC}$ emission of the fuel mixture is higher than the diesel at all loads. The INOP of 220 bar results in higher $\mathrm{HC}$ emission as compared to other INOPs and there is a slight variation in the HC emission of 180 and 200 INOPs. However, the INOP of 200 bar results in lower HC emission and this may be due to better combustion of the fuel. It is reported in the literature that the TPO has higher aromatic content which may result in incomplete combustion and more $\mathrm{HC}$ emission [21]. 
The oxides of nitrogen (NOx) emission of diesel, mixture of fuel at different INOPs is shown in the Figure 8. From the figure it is observed that the engine NOx emission increases with increase in load and this may be due to consumption of higher amount of fuel at higher loads which results in higher combustion temperature. The NOx emission is lower with the fuel mixture at lower INOPs such as 180 and 200 bars. This may be due to lower combustion temperature of the mixture. The NOx emission of the mixture at higher INOP of 220 bar results in higher NOx emissions at higher loads as compared to other INOPs.

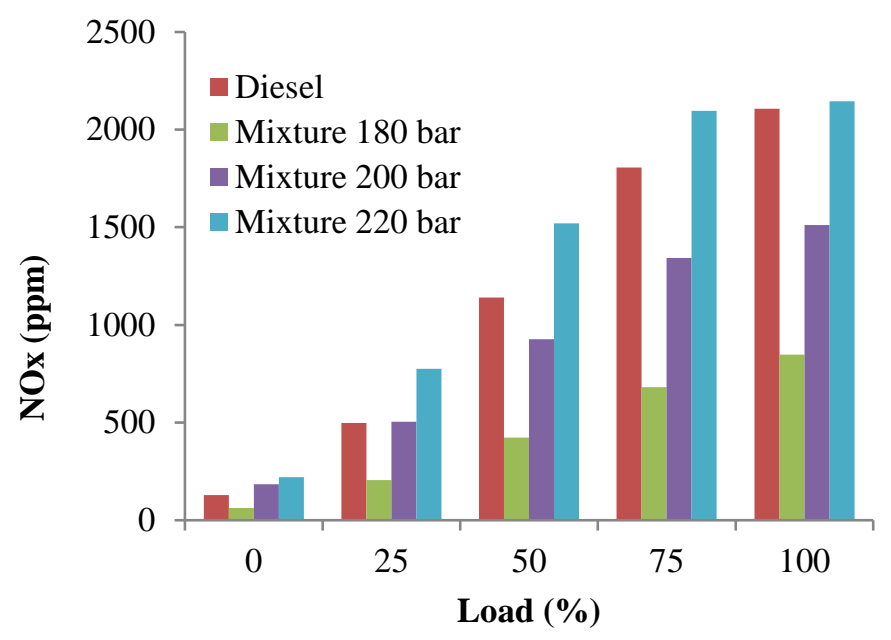

Fig. 8 NOx Versus Load

Figure 9 shows the variation in smoke emission of the diesel engine at different INOPs and at various loads. With an increase in the brake load, the air fuel ratio decreases due to increase in fuel injected and this results in higher smoke emission. From the figure it is observed that the smoke emission of the mixture is higher than the diesel at all loads. The smoke emission of mixture is lower with the INOP of $200 \mathrm{bar}$ as compared to other INOPs. The presence of aromatic content in the TPO results in higher smoke emission and this trend is similar to the results published in the literature.

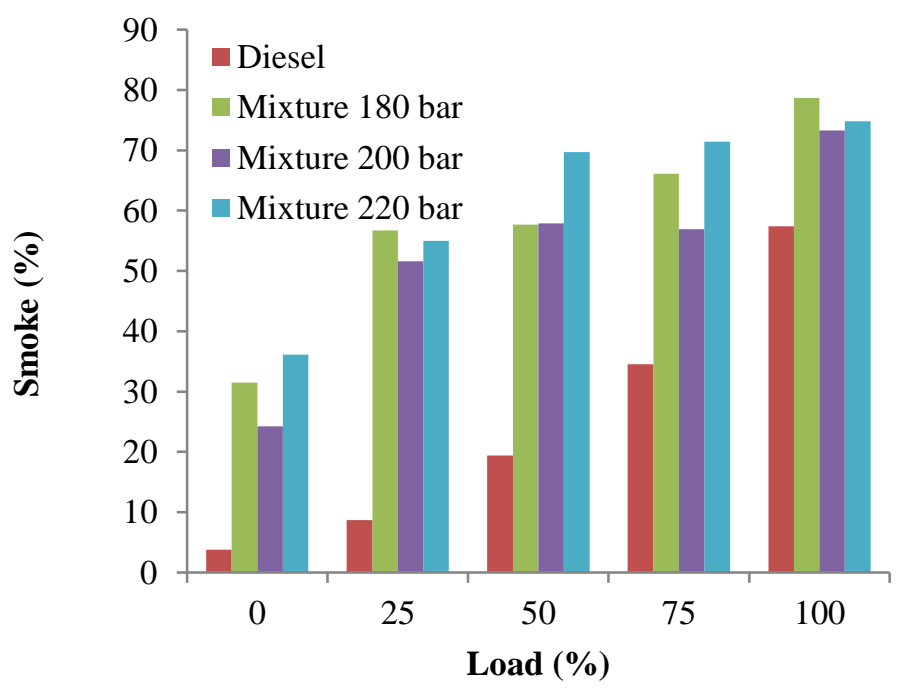

Fig. 9 Smoke Versus Load 
From this work, we observed that the TPO can be mixed with the honge biodiesel and the mixture can be used as fuel in the compression ignition engine. The INOP affects the engine performance parameter and the exhaust emissions. The INOP can be optimized to get better brake thermal efficiency and lower emissions as the INOP affects the fuel atomization, spray formation and combustion of the fuel. In literature it is reported that the INOP has to be optimized to get better thermal efficiency and lower emissions

\section{CONCLUSION}

In this work, biodiesel was prepared from non-edible honge oil and mixed with the TPO. The properties of fuel mixture of biodiesel and TPO were better than biodiesel and close to the properties of the diesel. The addition of TPO improves the volatility and viscosity of the biodiesel. The engine runs smoothly without any problems with the fuel mixture. The injector nozzle opening pressure significantly affects the engine performance and emissions. The INOP of 200 bar results in better performance and lower emissions as compared to other INOP. From this work, we conclude that the TPO can be used as a partial substitute for the honge biodiesel with higher INOP.

\section{REFERENCES}

[1] Girdhar Joshi, K. Jitendra, Pandey, Sravendra Rana, Devendra S. Rawat. Challenges and opportunities for the application of biofuel. Renewable and Sustainable Energy Reviews 2017 (79), 850 - 866.

[2] H. M. Mahmudul, F. Y. Hagos, R. Mamat, A. AbdulAdam, W. F. W. Ishak, R. Alenezi. Production, characterization and performance of biodiesel as an alternative fuel in diesel engines - A review. Renewable and Sustainable Energy Reviews 2017 (72), 497 - 509.

[3] Hakan Caliskan. Environmental and enviroeconomic researches on diesel engines with diesel and biodiesel fuels. Journal of Cleaner Production 2017 (154), 125 - 129.

[4] H. M. Mahmudul, F. Y. Hagos, R. Mamat, A. AbdulAdam, W. F. W. Ishak, R. Alenezi. A review on the prospects of sustainable biodiesel production: A global scenario with an emphasis on waste-oil biodiesel utilization. Renewable and Sustainable Energy Reviews 2017 (72), 445 - 464.

[5] M. Lalatendu. Turning waste tyre into 'green steel', Mumbai, The Hindu 2016 http://www.thehindu.com/business/Turning-waste-tyre-into-\%E2\%80\%98greensteel\%E2\%80\%99/article14518524.ece (browsed on 1st June, 2017)

[6] Juan Daniel Martínez, Magín Lapuerta, Reyes García Contreras, Ramón Murillo, Tomás García. Fuel properties of tire pyrolysis liquid and its blends with diesel fuel. Energy Fuels 2013 (27), 3296 - 3305.

[7] Abdulkadir Ayanoğlua, Recep Yumrutaşb. Production of gasoline and diesel like fuels from waste tire oil by using catalytic pyrolysis. Energy 2016 (103), 456 - 468.

[8] Ma Xiaolong, Dmitry Ridner, Zhang Zisheng, Li Xinganga, Li Honga, Sui Honga, GaoXina. Study on vacuum pyrolysis of oil sands by comparison with retorting and nitrogen sweeping pyrolysis. Fuel Processing Technology 2017 (163), 51 - 59.

[9] Siyi Luo. Yu Feng. The production of fuel oil and combustible gas by catalytic pyrolysis of waste tire using waste heat of blast-furnace slag. Energy Conversion and Management 2017 (136), 27 - 35.

[10] Yunpu Wang, Leilei Dai, Liangliang Fan, Dengle Duana, Yuhuan Liua, Roger Ruana, Zhenting Yua, YuezhenLiua, LinJianga. Microwave-assisted catalytic fast co-pyrolysis 
of bamboo sawdust and waste tire for bio-oil production, Journal of Analytical and Applied Pyrolysis 2017 (123), 224 - 228.

[11] J. A. Conesa, I. Martín-Gullón, R. Font, Jauhiainen. Complete study of the pyrolysis and gasification of scrap tires in a pilot plant reactor. Environmental Science and Technology 2004 (38), 3189 - 3194.

[12] Erick Ryoiti Umeki, Camilla Fernandesde Oliveira, Ricardo Belchior Torres, Ronaldo Gonçalvesdos Santos. Physico-chemistry properties of fuel blends composed of diesel and tire pyrolysis oil. Fuel 2016 (185), 236 - 242.

[13] M. N. Islam, M. R. Nahian. Improvement of waste tire pyrolysis oil and performance test with diesel in CI Engine, Journal of Renewable Energy 2016, Article ID 5137247, 1 -8 .

[14] I. De Marco Rodriguez, M. F. Laresgoiti, M. A. Cabrero, A. Torres, M. J. Chomón, B. Caballero. Pyrolysis of scrap tyres. Fuel Processing Technology 2001 (72), 9 - 22.

[15] T.J. Pilusa. The use of modified tyre derived fuel for compression ignition engines, Waste Management 2017 (60), 451 - 459.

[16] Ertaç Hürdoğan, Coskun Ozalp, Osman Kara, Mustafa Ozcanli. Experimental investigation on performance and emission characteristics of waste tire pyrolysis oildiesel blends in a diesel engine. International Journal of Hydrogen Energy 2017 (42) 23373 - 23378.

[17] A. Chríbik, M. Polóni, J. Lach, L. Jančošek, P. Kunc, J. Zbranek. Internal combustion engine powered by synthesis gas from pyrolysed plastics. Journal of Mechanical Engineering - Strojnícky časopis 2016 (66), No. 1, 37 - 46.

[18] M. Mlkvik, R. Olšiak, M. Smolar. Comparison of the viscous liquids spraying by the OIG and the oil configurations of an effervescent atomizer at low inlet pressures. Journal of Mechanical Engineering - Strojnicky časopis 2016 (66), No. 1, 53 - 64.

[19] Avinash Kumar Agarwal, Atul Dhar. Experimental investigations of performance, emission and combustion characteristics of karanja oil blends fuelled DICI engine, Renewable Energy 2013 (52), 283 - 291.

[20] N. Kapilan, C. B. Sekar. Production and evaluation of storage stability of honge biodiesel. Annals of the Faculty of Engineering Hunedoara 2011 (9), 267 - 269.

[21] B. S. Chauhan, N. Kumar, H. M. Cho. A study on the performance and emission of a diesel engine fueled with jatropha biodiesel oil and its blends. Energy 2012 (37) 616 22. 